\title{
Mutatis mutandis in corpore
}

\author{
Ivana dos Santos Teixeira* \\ Alex Branco Fraga**
}

\begin{abstract}
Resumo: Esta resenha do livro Corpos Mutantes: ensaios sobre novas (d)eficiências corporais, organizado por Edvaldo Couto e Silvana Goellner, editado pela Universidade Federal do Rio Grande do Sul (2007), tem por objetivo analisar as peculiaridades investigativas de cada manuscrito em relação ao tema central da coletânea: as tecnologias de reparação/ potencialização da performance humana.
\end{abstract}

Palavras-chave: Corpo humano. Características culturais. Revisão.

Corpos Mutantes: ensaios sobre novas (d)eficiências corporais é uma coletânea de dez textos que se articulam analiticamente em torno da potencialização da performance humana gerada por uma sofisticada maquinaria de mutação corporal. Escritos sob a ótica da Educação Física, educação, comunicação, filosofia, enfermagem e artes, a obra destaca-se pela consistência teórica de cada texto e pela unidade temática do conjunto. A leitura flui sem sobressaltos porque há coesão e coerência textual do início ao fim, algo difícil de conseguir em coletâneas. A cuidadosa seleção dos originais e a harmoniosa organização dos manuscritos são frutos de um projeto editorial muito bem concebido por Edvaldo Couto e Silvana Goellner, responsáveis pela organização da coletânea; e bem executado pela editora da UFRGS.

Apesar de não haver menção direta à origem e aos critérios de ordenamento dos manuscritos na apresentação do livro, é possível

\footnotetext{
Mestranda do Programa de Pós-Graduação em Ciências do Movimento Humano da Universidade Federal do Rio Grande do Sul (PPGCMH/UFRGS). Integrante do Grupo de Estudos sobre Cultura e Corpo (GRECCO). E-mail: ivanasteixeira@ gmail.com

" Doutor em Educação pela Universidade Federal do Rio Grande do Sul (UFRGS). Professor da Escola de Educação Física (ESEF) e do Programa de Pós-Graduação em Ciências do Movimento Humano (PPGCMH) da Universidade Federal do Rio Grande do Sul (UFRGS). Co-líder do Grupo de Estudos sobre Cultura e Corpo (GRECCO). E-mail: brancofraga@gmail.com
} 
classificá-los em dois grandes grupos: os teórico-reflexivos e os empírico-analíticos.

"Corpo, fragmentos e ligações: a micro-história de alguns órgãos e de certas promessas", de Ieda Tucherman; "Corpo cyborg e o dispositivo de novas tecnologias", de Homero Lima; e "Uma estética para os corpos mutantes", de Edvaldo Couto, fazem parte do primeiro grupo. São textos que funcionam como uma espécie de fio condutor da coletânea, pois apresentam, sob perspectivas e enfoques distintos, o quadro conceitual "pós-humano" que dá sentido às análises sobre técnicas de reparação das deficiências e/ou otimização das eficiências corporais presentes nos trabalhos subseqüentes. Um trecho do texto de Edvaldo Couto ilustra bem o conjunto da obra:

\begin{abstract}
Vivemos uma época de importantes conquistas técnico-científicas - implantes, transplantes, órgãos artificiais, mapeamento genético, clonagem, produção industrial de kits de testes para diagnósticos, novos medicamentos etc. - que permitem a sobrevivência de doentes que estariam condenados a morrer em pouco tempo e, principalmente, o aperfeiçoamento corporal de pessoas que desejam melhorar a aparência e performance em geral ( $\mathrm{p}$. 49-50).
\end{abstract}

Os outros sete textos compõem o segundo grande grupo. Diferenciam-se dos anteriores por serem, basicamente, excertos ou desdobramentos de dissertações e teses desenvolvidas nos Programas de Pós-Graduação da Universidade Federal do Rio Grande do Sul (UFRGS), instituição de origem da organizadora, e da Universidade Federal da Bahia (UFBA), instituição de origem do organizador. Afora "Corpus ex machina: contatos imediatos porque mediados", de Mara Vargas e Dagmar Meyer, extraído da dissertação de mestrado em educação da primeira autora e orientado pela segunda, os outros manuscritos vinculados à UFRGS foram desenvolvidos no Programa de Pós-Graduação em Ciências do Movimento Humano (PPGCMH) sob orientação de Silvana Goellner. Já os trabalhos oriundos dos programas de pós-graduação da UFBA (Artes Visuais e Comunicação e Cultura) foram desenvolvidos sob orientação de Edvaldo 
Couto. São, portanto, resultado de investigações acadêmicas de longo fôlego sobre mutações corporais das mais diversas ordens.

Tomando como referência o foco investigativo deste grupo de textos empírico-analíticos é possível desdobrar, independentemente da instituição de origem, mais dois subconjuntos: os que estão predominantemente centrados na reparação do corpo em função de alguma perda (da juventude, de um determinado órgão ou de um movimento do corpo etc.); e os que estão centrados na otimização da performance física (treinamentos, substâncias químicas, informática etc.).

"Velhice, palavra quase proibida; terceira idade, expressão quase hegemônica", de Annamaria Palácios, pertence ao primeiro subconjunto. Ela analisa a mudança discursiva resultante da paulatina substituição do vocábulo velhice (negativo) pelo vocábulo terceira idade (positivo) em anúncios publicitários de cosméticos. Palácios aponta que tal mudança não significa ruptura com a jovialidade como referência estética central, pelo contrário. Associar velhice à decrepitude física e terceira idade a um estado de ser jovial na maturidade não apenas reforça um padrão de beleza juvenil como também marca o envelhecimento como um déficit físico.

No texto "Corpos amputados e protetizados: 'naturalizando' novas formas de habitar o corpo na contemporaneidade", de Luciana Paiva, a idéia de reparação de uma deficiência é mais explícita. A autora descreve com muita sensibilidade como nove adultos pacientes de uma clínica especializada em reabilitação e protetização passaram a lidar com as próteses após a amputação de parte do corpo. Mostra a fase inicial da incorporação deste artefato em suas vidas e o modo como cada um deles passou a dar sentido a este processo de maquinização do próprio corpo.

Fechando este primeiro subconjunto, Varlei Novaes discute em "A performance do híbrido: corpo, deficiência e potencialização" os significados culturais atribuídos aos atletas que utilizam cadeiras de rodas produzidas com alta tecnologia para fins competitivos. $\mathrm{O}$ autor destaca que estas cadeiras não servem apenas como "veículo" de reparação do movimento, mas também como uma prótese que

Movimento, Porto Alegre, v. 14, n. 02, p. 233-238, maio/agosto de 2008. 
potencializa seus rendimentos esportivos. O autor emprega a noção de híbrido para problematizar a relação humano/máquina e mostrar como as fronteiras natural/artificial, orgânico/inorgânico têm sido borradas nesse processo e têm gerado novas identidades culturais.

Entre os textos associados ao subconjunto da otimização da performance destaca-se "O espetáculo do ringue: o esporte e a potencialização de eficientes corporais", de Cláudio Nunes e Silvana Goellner. Trata-se de um estudo de caráter etnográfico realizado em duas academias e um centro de treinamentos de Mixed Martial Arts (popularmente conhecida no Brasil como Luta Livre), que procura mostrar como os praticantes desta modalidade de luta exploram suas potências corporais em meio à rotina de treinamentos, competições e uso de substâncias químicas. O autor e a autora dão especial destaque ao trabalho de lapidação do corpo guerreiro que cada praticante se auto-impõe diariamente, visível na materialidade das "cicatrizes, músculos inflados e orelhas repolhudas" (p. 60).

"Os percursos do corpo na cultura contemporânea", de Malu Fontes, baseia-se no conceito de "corpo canônico" para analisar os crescentes investimentos femininos em programas de exercício físico, dietas, medicamentos, incisões cirúrgicas etc. São técnicas de otimização dos corpos mais sutis, mas não menos chamativas, pois elas demandam um detalhado ajuste do corpo às características físicas veiculadas como padrão estético pela mídia. Para a autora, o corpo canônico não se resume ao corpo belo, ele está ligado a "um corpo (re)construído a partir de um conjunto de discursos, práticas e procedimentos de várias naturezas que visam torná-lo culturalmente adequado, capaz de atender às exigências de uma corporeidade supostamente considerada ideal" (p. 83).

"Corpus ex machina: contatos imediatos porque mediados", de Mara Vargas e Dagmar Meyer, discute o processo de "ciborguização da enfermeira" em meio à prática terapêutica em Unidade de Tratamento Intensivo (UTI). Através da análise do algoritmo clínico, "descrição explícita dos passos a serem realizados no cuidado ao paciente em circunstâncias específicas" (p. 129), as autoras demonstram que o trabalho da enfermeira intensivista com pacientes de 
UTI em parada cardiorrespiratória só se realiza por intermédio da linguagem e da aparelhagem computacional que define, passo a passo, cada ação sobre o corpo enfermo. Trata-se de uma tecnologia cibernética que, ao mesmo tempo em que leva à reanimação de um paciente, dá "vida" à enfermeira intensivista.

O texto de Danillo Barata, "O corpo e a expressão videográfica: a videoinstalação como estratégia de uma narrativa corporal", não trata diretamente de técnicas de reparação dos corpos nem de técnicas de otimização da performance. Barata vale-se de duas videoinstalações para problematizar em sua pesquisa a busca obsessiva de correspondência entre a materialidade corporal de cada um com os corpos idealizados pelo mundo da moda. Apresentar em vídeo corpos dissonantes em ângulos não favoráveis ao olhar domesticado pela cultura fashion foi uma das estratégias utilizadas para potencializar a imagem de corpos transgressores à estética dominante. A diversidade física projetada nos vídeos produzidos para as instalações incomodava quem assistia, de acordo com o autor, o excesso de "normalidade" causa estranheza a quem está acostumado com a exuberância corporal em formato televisivo.

"Corpos Mutantes" é uma coletânea de textos bem alinhavados em torno das tecnologias de transformação das materialidades e das subjetividades corporais. Não há apologia ou aversão à biotecnologia, há, isto sim, um chamado à discussão sobre nossa condição pós-humana por meio da análise do impacto das diversas técnicas de configuração dos corpos: cirurgias, transplantes, próteses, cosméticos, treinamentos, medicamentos, implantes, informática etc. Uma maquinaria que estabelece os contornos de novas práticas, novas identidades, novos preconceitos, novas marginalizações e novas representações culturais. Trata-se de um contexto social cada vez mais comum e, paradoxalmente, cada vez mais estranho.

Cabe salientar, por fim, que as divisões que estabelecemos na construção desta resenha tiveram por objetivo dar destaque às peculiaridades dos textos, independentemente da disposição no sumário, para evidenciar a complexidade temática e a bem sucedida composição do livro. Nossa idéia era dar visibilidade ao fio condutor 
que perpassa os objetos de estudo específicos de cada texto desta coletânea. É bem provável que os futuros leitores e leitoras interessadas no assunto encontrem outros fios que compõem esta instigante trama temática. Eis, aí, mais um bom motivo para embrenhar-se na leitura.

Movimento, Porto Alegre, v. 14, n. 02, p.233-238, maio/agosto de 2008. 
Abstract: This summary of the book Corpos Mutantes: ensaios sobre novas (d)eficiências corporais (Mutant bodies: assays about new corporal (d)efficiencies), organized by Edvaldo Couto and Silvana Goellner, edited by the Federal University of Rio Grande do Sul (2007), has the objective of analyzing the investigative peculiarities of each manuscript in relation to the collection's central theme: technologies for human performance repairing/potentialization.

Keywords: Human body. Cultural characteristics. Review.

Resúmen: Esta reseña del libro Cuerpos Mutantes: ensayos sobre nuevas (d)eficiencias corporales, organizado por Edvaldo Couto y Silvana Goellner, editado por la Universidad Federal de Rio Grande do Sul (2007), tiene por objetivo analizar las peculiaridades investigativas de cada manuscrito en relación al tema central de la colectanea: las tecnologías de reparación/ potencialización de la performance humana.

Palabras-clave: Cuerpo humano. Características culturales. Revisión.

\section{REFERÊNCIAS}

COUTO, E. S; GOELLNER, S.V. (Orgs.). Corpos mutantes: ensaios sobre novas (d)eficiências corporais. Porto Alegre: Editora da UFRGS, 2007. 